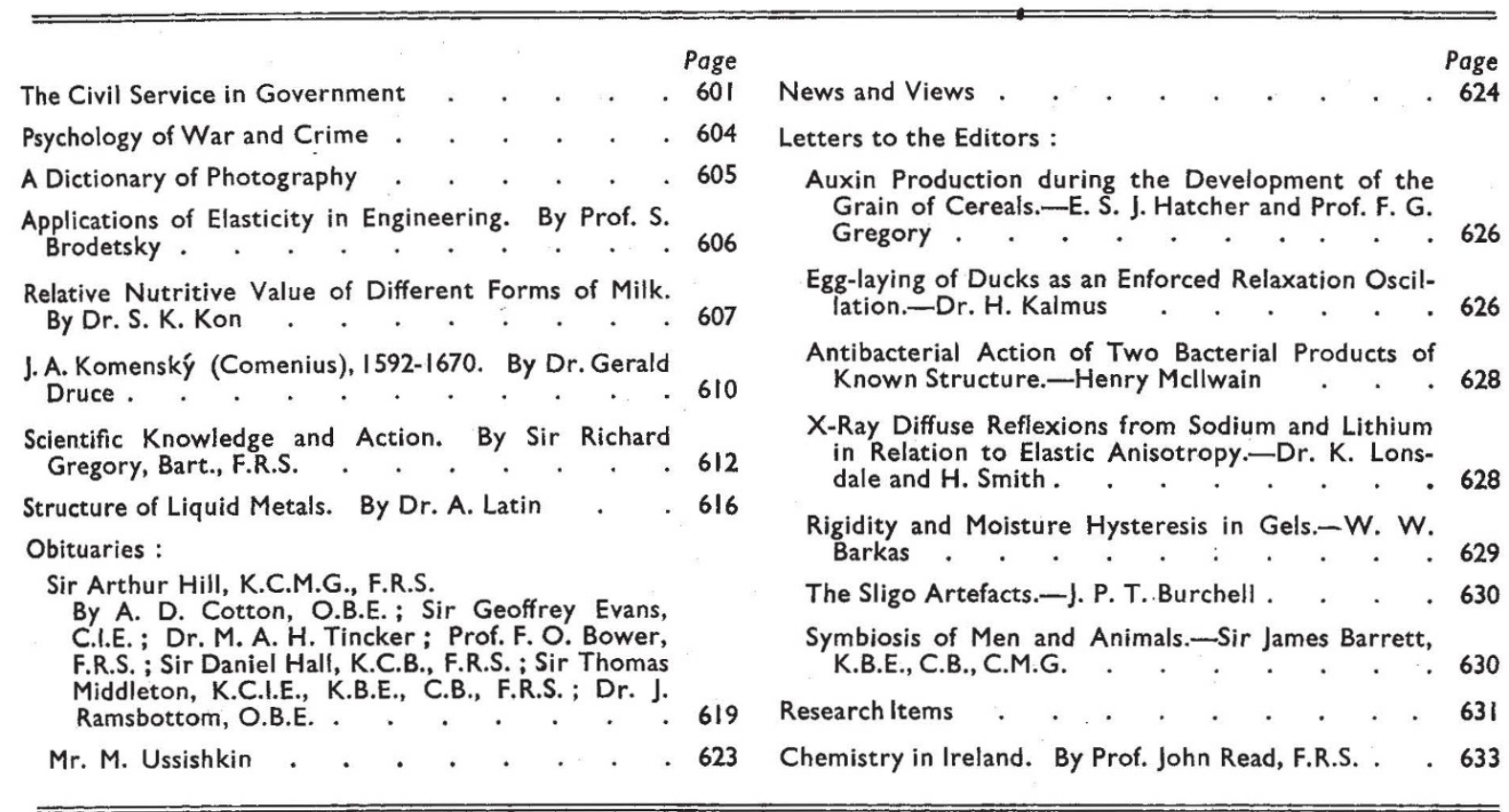

\title{
THE CIVIL SERVICE IN GOVERNMENT
}

$\mathrm{B}$ EHIND the less restrained and sometimes unfair criticism which has been levelled at the Civil Service as the War has continued, there has lain a vague, unformulated feeling that the Civil Service as a whole is slightly out of touch with the times, and neither in calibre nor technique quite so competent to handle the taisks with which it is confronted as was the Civil Service of a generation ago.

It is the great merit of a recent broadsheet, "The Machinery of Government", issued by Political and Economic Planning, that it brings such uneasiness into the light of day, probes its causes, and, setting the Civil Service in its proper perspective in relation to the task of government, makes constructive proposals for removal of many of the defects revealed.

In the first place, as the broadsheet points out, there is no peculiar 'democratic virtue' in incompetent administration; modern government is increasingly a matter of determining the right priorities in the broadest sense, of educating public opinion to those priorities, and of adjusting organization and methods to give them the fullest and most immediate effect. The failure of our executive machinery of government to plan ahead, its failure continuously to adjust its working structure and technique to the problems with which it is called upon to deal, its continued domination by financial and accounting aspects, its neglect of scientifie and technical advances and its timidity in accepting responsibility, all flow from a failure to renounce the old conception of government as a regulatory, policing and taxing mechanism; and openly to adopt the conception of government as the nation's common instrument for expanding its social and economic welfare in all those spheres where individuals or private associations cannot achieve equally effective results.

Although some improvement is being effected through the creation of new organizations and the elimination of weak spots, apart from the important exception of Mr. Eden's proposed reforms at the Foreign Office and in the Diplomatic Service, there has been little sign of the radical change of outlook involved in this new conception of government. Moreover, in reviewing the complex machinery of central government, as the broadsheet points out, it is important to consider Parliament, Ministers and the Civil Service, not in isolation but in their mutual actions and reactions. The Minister, for example, is to a very great degree dependent on the advice of the full. time professional officers of his Department for the policies which he submits to his colleagues in the Cabinet. In the execution of these policies 
he can do little to secure more vigorous or effective action if the machine of which he is temporarily in charge is rusty or otherwise defective. No individual Civil Servant should be blamed for the consequences where advice he has given has been ignored by the Minister or by the Cabinet, but the Civil Service as a body must bear a fair share of the responsibility if the techniques for obtaining information and for shaping and presenting policy are such that too high a proportion of decisions prove to be ill-advised. The Civil Service, as a body, given the knowledge and the will to do so, is in a position to alter those techniques : generally speaking, the individual Minister is not.

The P E P broadsheet, leaving for a later statement the political and ministerial elements in the problem, discusses the main weaknesses of the Civil Service and how they might be corrected. It carries into constructive detail the ideas to some extent outlined by Dr. W. A. Robson in his introductory essay in "The British Civil Servant" some four years ago, and forms an admirable complement to the study of the growth of the British Civil Service, 1780-1939, by Emmeline W. Cohen*. There is indeed no simple or magic remedy. The solution lies partly in the change in the basic attitude to the task already emphasized, partly in some changes and derelopments of organization, partly in the modernization of methods and the use of available resources and techniques which have hitherto been neglected. Behind it all lies the problem of choosing the right men and using their abilities to the full.

It will readily be conceded that in present circumstances it would be impossible and highly dangerous to attempt a complete reorganization of the Civil Service. Modification of the recruitment, training and development of a great professional body is a long-period undertaking, which can only take effect over several decades. Fortunately, however, the measures which are immediately possible do not appear to conflict with the long-range measures required to equip the country to face the tasks which will meet it at the end of the War.

The analysis of the Civil Service in this broadsheet points once more to the weakness of the Service in knowledge of social and natural science, and in grasp of scientific method or technique. Training is in general political and administrative rather than executive. There is little knowledge of the new techniques of large-scale organization and management which have been developed in the last forty years, and an imperfect appreciation of the fact-finding method of approach to problems of administration on which these techniques are based. Even less than in industry the distinction

*The Growth of the British Civil Service, 1780-1939. By Emmeline W. Cohen. Pp. 222. (London: George Allen and Unwin, Ltd., 1941.) 108. $6 d$ net. of staff from line functions is not properly recognized, and there is no conception of holding any of the strength in reserve for emergencies-a criticism which equally applies to a large part of industry.

These severe criticisms find support in a recent important study of the advisory bodies, on which the Haldane Report laid such stress ; indeed the analysis reiterates not a few of the criticisms contained in that Machinery of Government Committee's report of twenty-three years ago. The emphasis laid there on the need for further provision for the continuous acquisition of knowledge and the prosecution of research, and on the desirability of establishment departments keeping themselves acquainted with what is being done in the business world are at once recalled by comments in the present broadsheet.

At the same time, it should be remembered that the adoption of a fact-finding technique by the Civil Service has sometimes been checked or discouraged rather than welcomed. The rebuke administered in the Times Educational Supplement to the Board of Education regarding a memorandum compiled by officers of the Board as a basis for discussion on the nation's next moves in educational planning is a recent example. If responsible opinion is to stigmatize such initiative as a grave constitutional novelty it is unlikely, to say the least, that the type of administrator now so urgently needed will be forthcoming.

The truth is that the weaknesses of the Civil Service are due, not to incapacity, but to a group of inhibitions and an absolute conception of government, which must be overthrown by the force of public opinion. That is the first step to securing that the Civil Service recognizes its function in safeguarding and developing the collective inheritance and the social and economic welfare of the nation, as well as that of preserving and assisting to enrich the individual liberties of its citizens. Only public opinion can secure the change from an agenda of public business, determined by external pressures, to one determined by the needs and facts of the situation, based upon thorough intelligence, careful forecasting and continuous analysis of the problems affecting the particular branch of government, and of the best ways of meeting them within the limits of general policy decided by Ministers and approved by Parliament. That change involves a radical alteration in the criteria applied in public administration-a shift in emphasis away from reliance on precedent, consistency and the avoidance of trouble from minority groups, towards action based on a thorough survey of the situation, a sound judgment of its implications and a clear perception of both in the minds of all the officers and departments concerned. 
The first main conclusion of the P E P survey, then, is that this new conception of the function of government, with all that it implies for the Civil Service in changes in outlook, organization and methods, and in its relation to Ministers, should be fully and frankly faced. This conception was in fact equally implicit at the recent Conference on Science and World Order, not merely in the session devoted specifically to science and government, but also in those devoted to the relation of science to human needs and to post-war relief. The speeches of Mr. Eden and Mr. Morrison in connexion with the Conference indicate that the Government in Great Britain is now alive to these implications, and scientific workers may well be encouraged by the Conference to further efforts towards the formation of the public opinion essential for Parliamentary support.

From this it follows that the Cabinet secretariat must somehow be permanently strengthened in powers and personnel in co-operation with the departments concerned, to exercise the three functions of planning, personnel management and budgetary control, which are of decisive importance in determining the scope and efficiency of the machinery of government. This involves keeping continuously under review the main strategic conditions affecting government in the economic and social fields, presenting and examining the possible alternative courses, and putting them up for decision in order to elicit from Ministers the necessary directives on policy and priorities affecting groups of departments. The organization would also be responsible for working out with departmental officers the application of such directives to particular circumstances, for seeing that action is taken and for recording and circulating suitably digested information regarding it. Such an organization would not only supply the machinery for central planning and co-ordination; it would also supply the equally important mechanism for following up and seeing that approved policies are effectively and promptly put into operation.

The same fundamental conclusion regarding the Treasury is reached by the P E P broadsheet as in the Haldane Report. The recommendation that this should become purely the Department of Public Finance and the Budget, with a modernized outlook and methods, is the reflexion of criticism of the traditional attitude of antagonism between the Treasury and other departments. It is a reminder of the comment in the Haldane Report that the obligation of spending departments to formulate a full and reasoned statement of their proposals places upon the Treasury a corresponding obligation not to assume a negative attitude in the first instance towards suggestions for improving the quality of a service or the efficiency of the staff which administers it.

In the same train of thought follows the recommendation that the management and control of personnel matters should be delivered from finance, but the P E P broadsheet goes far beyond the Haldane Committee in recommending the formation of a central personnel office by transfer to a reconstituted Civil Service Commission with a suitably qualified membership, not limited to Civil Servants, of the establishment and office organization function of the Treasury. In political matters this Commission should be directly responsible to the Prime Minister. This step should be taken immediately, even if some of its long-term implications cannot be worked out until after the War.

This and other recommendations, like those for the establishment of a staff college for the higher training of men and women destined for high administrative or executive responsibilities, and the introduction into each department of the organization and techniques necessary for effective forecasting and planning ahead, or again the modification of methods of recruitment, training and grading so as to bring the ablest men rapidly to the top and eliminate the waste of good material, are in harmony with modern scientific administration and the best practice of large-scale industry. So, too, is the suggestion that the scope normally assigned to scientific workers and to technical experts should be enlarged. The broadsheet in fact reflects the essential criticism contained in many recent discussions of the Civil Service.

There can be no doubt that this searching analysis goes to the root of the troubles which have prompted much recent criticism of the Civil Service, fair or unfair. If it seems disappointing to find so little effect has been given to authoritative recommendations formulated more than two decades ago, Emmeline Cohen's book provides an admirable corrective. For all its weaknesses, the British Civil Service is a growing service, adapting itself continuously to changed conditions. The rate of change may lag behind what is desirable, but that can be accelerated by the pressure of public opinion. The suggesstions in the P E P broadsheet would go far to secure the greater flexibility required within the Service, the increased mobility between it and the external world, the new conception of the task confronting the Service and the dissemination throughout the Service of a new outlook and new methods. What is required to secure the adoption of such methods and the placing of new men in key positions is the steady pressure of public opinion, in the formation of which scientific workers themselves have an important part to play. 